DIREITO PROCESSUAL PENAL

COMENTÁRIO À JURISPRUDÊNCIA

\title{
PROCEDIMENTO ESPECIAL DO JÚRI - NÃO APLICAÇÃO DO ARTIGO 155 DO CÓDIGO DE PROCESSO PENAL - POSSIBILIDADE DA DECISÃO DE PRONÚNCIA EMBASAR-SE EM PROVAS PRODUZIDAS EM FASE INQUISITORIAL
}

\author{
LUCIANA PERPÉTUA CORRÊA \\ Promotora de Justiça \\ Ministério Público do Estado de Minas Gerais, Brasil \\ lucianacorrea@mp.mg.gov.br
}

\section{Considerações iniciais}

O Supremo Tribunal Federal publicou decisões reiteradas no sentido de que a decisão de pronúncia pode ter embasamento somente em depoimentos colhidos na fase inquisitorial, não se aplicando o artigo 155 do Código de Processo Penal Brasileiro. No mesmo sentido, há também julgados do Egrégio Tribunal de Justiça do Estado de Minas Gerais.

É notório que na fase do sumário de culpa que se encerra com a pronúncia, apura-se somente se há nos autos elementos que demonstram a materialidade delitiva $\mathrm{e}$ indícios de autoria, consubstanciando juízo de admissibilidade para garantir o julgamento dos delitos contra a vida ao Tribunal do Júri, em sessão plenária, cuja análise meritória deve necessariamente ser submetida aos jurados, nos termos da Constituição Federal de 1988.

Ocorre que os jurisconsultos e estudiosos da matéria, em sua maioria, não enfrentam a questão em seus estudos. Trata-se de 
constatação compreensível, já que os grandes oradores que compõe o Tribunal do Júri em nosso país, em sua maioria, não possuem perfil acadêmico e têm grande dificuldade de realizar publicações, em virtude da imensa quantidade de serviço.

Dessa forma, muitos estudiosos que escrevem sobre o assunto ignoram completamente as peculiaridades do procedimento especial do Tribunal do Júri e a praxis forense, tratando a matéria na vala comum, o que implica várias conclusões teratológicas sobre o assunto.

O comentário à jurisprudência colacionada é de significativa importância prática aos promotores de Justiça, magistrados e advogados, os quais laboram em processos que envolvem crimes dolosos contra a vida, porque certamente já enfrentaram a questão ou irão fazê-lo brevemente.

\section{Jurisprudência do Supremo Tribunal Federal}

HC 112507 MC/DF - DISTRITO FEDERAL

MEDIDA CAUTELAR NO HABEAS CORPUS

Relator(a): Min. RICARDO LEWANDOWSKI

Julgamento: 06/03/2012

Publicação

PROCESSO ELETRÔNICO

DJe-048 DIVULG 07/03/2012 PUBLIC 08/03/2012

Partes

PACTE.(S): J. A. F. N.

IMPTE.(S): DEFENSORIA PÚBLICA DA UNIÃO

PROC.(A/S) (ES): DEFENSOR PÚBLICO-GERAL FEDERAL

COATOR(A/S) (ES): SUPERIOR TRIBUNAL DE JUSTIÇA 


\section{Decisão}

Trata-se de habeas corpus, com pedido de liminar, impetrado pela Defensoria Pública da União, em favor de J. A. F. N. contra acórdão da Quinta Turma do Superior Tribunal de Justiça, que denegou a ordem pleiteada no HC 104.240/PI, Rel. Min. Marco Aurélio Bellizze.

Consta dos autos que o paciente foi pronunciado pela suposta tentativa de homicídio duplamente qualificado (art. 121, $\S 2^{\circ}$, II e IV, combinado com o art. 14, II, do CP).

A impetrante relata, em seguida, que, buscando a anulação da sentença de pronúncia por ausência de provas suficientes de autoria, o paciente interpôs recurso em sentido estrito no Tribunal de Justiça do Estado do Piauí, que negou provimento ao recurso.

Inconformada, a defesa impetrou babeas corpus no Superior Tribunal de Justiça, que denegou a ordem, em acórdão assim ementado:

PENAL E PROCESSUAL PENAL. HABEAS CORPUS. TENTATIVA DE HOMICÍDIO DUPLAMENTE QUALIFICADO. (I) ARGUIÇÃO DE NULIDADE DA DECISÃO DE PRONÚNCIA FUNDADA EXCLUSIVAMENTE EM PROVA COLHIDA EM FASE INQUISITORIAL. INVIABILIDADE. INDICAÇÃO DE PROVAS SUBMETIDAS AO CRIVO DO CONTRADITÓRIO E DA AMPLA DEFESA. (II) ALEGAÇÃO DE FRAGILIDADE DOS FATOS INDICADOS NA DENÚNCIA. IMPROCEDÊNCIA. CORRETA INDICAÇÃO DE INDÍCIOS DE AUTORIA E CERTEZA DA MATERIALIDADE DO FATO CRIMINOSO. ORDEM DENEGADA.

1. Não há nulidade processual se a decisão de pronúncia, para admitir a tese veiculada na denúncia, funda-se em elementos de prova colhidos em juízo, mesmo que eventualmente mencione informações colhidas durante o inquérito policial. Ademais, a impetrante não trouxe elementos aptos a desconstituir o alegado pela Corte estadual, não constando dos autos documento que demonstre que os depoimentos utilizados na sentença de pronúncia foram somente aqueles prestados perante a autoridade policial. 
2. O entendimento desta Corte Superior vem se firmando no sentido de que a sentença de pronúncia pode se valer de elementos probatórios colhidos na fase inquisitorial, por não configurar juízo de certeza. Precedentes.

3. É regular a decisão de pronúncia e o acórdão que a confirma se há indicação de elementos suficientes a demonstrar a probabilidade da autoria, bem como a certeza sobre a materialidade do fato criminoso, de maneira a atestar a possível adequação da conduta aos dispositivos - art. 121, $\S 2^{\circ}$, incisos II e IV, c/c art. 14, II, do CP - que embasaram a submissão do feito ao colegiado popular.

4. Habeas corpus denegado.

$[\ldots]$

Indefiro a medida liminar.

Dispenso as informações da autoridade apontada como coatora.

Oficie-se, contudo, ao Juízo de Direito da Comarca de Ipiranga do Piauí, para que informe o atual andamento da ação penal movida contra o paciente (Processo 32/2004).

Com as informações, ouça-se o Procurador-Geral da República.

Publique-se.

Brasília, 6 de março de 2012.

Ministro RICARDO LEWANDOWSKI

No mesmo sentido:

HC 112626 MC / SP - SÃO PAULOMEDIDA CAUTELAR NO HABEAS CORPUS

Relator(a): Min. RICARDO LEWANDOWSKI

Julgamento: 14/03/2012 
Publicação

PROCESSO ELETRÔNICO

DJe-055 DIVULG 15/03/2012 PUBLIC 16/03/2012

Partes

PACTE.(S): F. L. R. L.

IMPTE.(S): DEFENSORIA PÚBLICA DO ESTADO DE SÃO PAULO

PROC.(A/S) (ES): DEFENSOR PÚBLICO-GERAL DO ESTADO DE SÃO PAULO

COATOR (A/S) (ES): SUPERIOR TRIBUNAL DE JUSTIÇA

\section{Decisão}

Trata-se de habeas corpus, com pedido de medida liminar, impetrado pela Defensoria Pública do Estado de São Paulo, em favor de F. L. R. L, contra acórdão da Quinta Turma do Superior Tribunal de Justiça, que denegou a ordem pleiteada no HC 113.754/ SP, Rel. Min. Adilson Vieira Macabu (Desembargador convocado do TJ/RJ).

A impetrante narra, de início, que o paciente foi denunciado, com outra pessoa, pela suposta prática dos crimes de homicídio duplamente qualificado (art. 121, I e IV, do CP).

Relata ainda que, após a formação da culpa, o paciente foi impronunciado pela Magistrada do Juízo do I Tribunal do Júri de São Paulo, que entendeu não serem suficientes as provas colhidas exclusivamente na fase inquisitorial, para a submissão do réu ao júri popular.

Inconformado, o Parquet estadual interpôs recurso em sentido estrito no Tribunal de Justiça do Estado de São Paulo, que deu parcial provimento ao recurso, submetendo o paciente ao Tribunal do Júri. 
Consta dos autos ainda que, buscando o restabelecimento da sentença de impronúncia, a defesa impetrou habeas corpus no Superior Tribunal de Justiça, que denegou a ordem, em acórdão assim ementado:

'HABEAS CORPUS. HOMICÍDIO QUALIFICADO. DECISÃO DE PRONÚNCIA FUNDAMENTADA EM PROVAS COLHIDAS NO INQUÉRITO POLICIAL. POSSIBILIDADE.

1. O juízo de pronúncia limita-se à admissibilidade do fato delituoso, sem manifesta procedência da pretensão punitiva, cuja competência constitucional é conferida ao Tribunal do Júri.

2. Diante disso, é possível a pronúncia ser fundamentada em provas colhidas na fase inquisitorial.

3. Ordem denegada'.

Publique-se.

Brasília, 14 de março de 2012.

Ministro RICARDO LEWANDOWSKI

Nesse caminho, também os E. Desembargadores do Egrégio Tribunal de Justiça do Estado de Minas Gerais já se manifestaram a respeito do assunto.

O Desembargador Delmival de Almeida Campos, em acórdão prolatado no Egrégio Tribunal de Justiça do Estado de Minas Gerais, em seu voto, asseverou:

RECURSO EM SENTIDO ESTRITO - TENTATIVA DE HOMICÍDIO - PROVA DA MATERIALIDADE - SUSTENTADA AUSÊNCIA DE PROVAS EM RELAÇÃO À AUTORIA - IMPRONÚNCIA - PROVA TESTEMUNHAL - SUFICIÊNCIA DE INDÍCIOS - DÚVIDA CARACTERIZADA - IN DUBIO PRO SOCIETATE - MATÉRIA QUE COMPETE AO TRIBUNAL DO JÚRI - DECISÃO MANTIDA - RECURSO DESPROVIDO. A decisão de pronúncia constitui mero juízo de admissibilidade da acusação e é fundada em suspeita, sendo su- 
ficiente, pois, para a sua prolação, apenas o convencimento do magistrado quanto à existência do crime e de indícios de autoria e/ou de participação, tendo por objetivo submeter o acusado ao julgamento perante o Tribunal do Júri. Lado outro, cuidando-se a impronúncia de "um julgamento de inadmissibilidade de encaminhamento da imputação para o julgamento perante o Tribunal do Júri”, tem-se que esta solução somente se impõe quando, de modo algum, seja possível o acolhimento da acusação por aquele e. Colegiado.

\section{$[\ldots]$}

Importante gizar que, em sede de pronúncia não há como aplicar, o ARTIGO 155 do Código de Processo Penal, porque, nessa fase, o Julgador limita-se a proferir um mero juízo de admissibilidade da peça acusatória, justamente para não interferir ou afastar indevidamente a competência do Tribunal do Júri.

Tal raciocínio se justifica porque o procedimento do júri é bifásico e, portanto, outras provas poderão ser produzidas em plenário, ou melhor, nada impede que aqueles elementos constantes do procedimento inquisitivo sejam reproduzidos e confirmados perante os jurados. Não fica, pois, a atuação da Defesa e do Ministério Público restrita às provas coligidas durante o sumário.

Neste sentido, os seguintes precedentes do Superior Tribunal de Justiça: HABEAS CORPUS. HOMICÍDIO QUALIFICADO TENTADO (ARTIGO 121, § $2^{\circ}$, INCISO IV, COMBINADO COM O ARTIGO 14, INCISO II, AMBOS DO CÓDIGO PENAL). DECISÃO DE PRONÚNCIA QUE ESTARIA FUNDAMENTADA APENAS EM ELEMENTOS COLHIDOS NA FASE POLICIAL. POSSIBILIDADE. HIPÓTESE EM QUE O MAGISTRADO DE ORIGEM MOTIVOU O SEU ENTENDIMENTO TANTO EM DEPOIMENTOS PRESTADOS PERANTE A AUTORIDADE POLICIAL, QUANTO EM TESTEMUNHO FORNECIDO EM JUIIZO. INEXISTÊNCIA DE CONSTRANGIMENTO ILEGAL. DENEGAÇÃO DA ORDEM.

1. Em respeito à garantia constitucional do devido processo legal, a legitimidade do poder-dever do Estado aplicar a sanção prevista em lei ao acusado da prática de determinada infração penal deve ser exercida por meio da ação penal, no seio da qual ser-lhe-á assegurada a ampla defesa e o contraditório. 
2. Visando afastar eventuais arbitrariedades, a doutrina e a jurisprudência pátrias já repudiavam a condenação baseada exclusivamente em elementos de prova colhidas no inquérito policial.

3. Tal vedação foi abarcada pelo legislador ordinário com a alteração da redação do ARTIGO 155 do Código de Processo Penal, por meio da Lei 11.690/2008, o qual prevê a proibição da condenação fundada exclusivamente nos elementos informativos colhidos na investigação.

4. Conquanto seja pacífica a orientação segundo a qual nenhuma condenação pode estar fundamentada exclusivamente em provas colhidas em sede inquisitorial, tal entendimento deve ser visto com reservas no que diz respeito à decisão de pronúncia.

5. Isso porque tal manifestação judicial não encerra qualquer proposição condenatória, apenas considerando admissível a acusação, remetendo o caso à apreciação do Tribunal do Júri, único competente para julgar os crimes crimes dolosos contra a vida.

6. Ademais, no procedimento do júri a prova testemunhal pode ser repetida durante o julgamento em plenário (ARTIGO 422 do Código de Processo Penal), sendo que a Lei Processual Penal, no ARTIGO 461, considerando a importância da oitiva das testemunhas pelos jurados, juízes naturais da causa, chega até mesmo a prever o adiamento da sessão de julgamento em face do não comparecimento da testemunha intimada por mandado com cláusula de imprescindibilidade.

7. Por tais razões, a jurisprudência consolidou-se no sentido de que a decisão de pronúncia pode ser fundamentada em elementos colhidos na fase policial (Precedentes do STJ e do STF).

8. Ainda que assim não fosse, na hipótese vertente tem-se que o magistrado de origem, ao considerar presentes a comprovação da materialidade e os indícios da autoria do homicídio qualificado em questão, fundamentou sua compreensão tanto em depoimentos prestados perante a autoridade policial, quanto no único testemunho colhido em juízo, decisão que foi mantida pelo Tribunal de origem. 
9. Ordem denegada (HC 127893/RS; Rel. Min. Jorge Mussi; DJ 08/11/10, grifo nosso).

PROCESSUAL PENAL. HABEAS CORPUS. ART. 121, § $2^{\circ}$, INCISO IV, C/C ART. 14, INCISO II, AMBOS DO CÓDIGO PENAL. PRONÚNCIA. PROVAS. IN DUBIO PRO SOCIETATE. QUALIFICADORA. MANUTENÇÃO.

I - Em se tratando de crime afeto à competência do Tribunal do Júri, o julgamento pelo Tribunal Popular só pode deixar de ocorrer, provada a materialidade do delito, caso se verifique ser despropositada a acusação, porquanto aqui vigora o princípio in dubio pro societate.

II - Diferente do que ocorre em relação à sentença condenatória, a decisão que pronuncia o acusado exige, tão somente, a presença de indícios de autoria, além de prova da materialidade do delito. Indícios estes que, por sinal, podem derivar de provas colhidas durante o inquérito policial. (Precedente do STF).

III - Somente poderão ser excluídas da $\mathrm{r}$. decisão de pronúncia as qualificadoras manifestamente improcedentes. (Precedentes). Writ denegado. Liminar cassada' (HC 53888/PR; Rel. Min. Felix Fischer; DJ 21/05/07). (TJMG - Processo n. 1.0023.08.008403-3. Rel. Des. Delmival de Almeida Campos. DJ. 28.09.2011, grifo nosso).

O Desembargador Pedro Vergara também se manifestou, em voto proferido no RSE 1.0024.08.970753-3/001:

A sentença de pronúncia encerra mero juízo de admissibilidade, sem maior exame do mérito da imputação, pois este é relegado aos jurados, não se aplicando, neste estágio processual, os ditames do artigo 155 do Código de Processo Penal. A exigência de provas judicializadas, presente no art. 155 do Código de Processo Penal, refere-se à decisão definitiva, não se podendo invocá-la em sede de pronúncia, mero juízo de admissibilidade, até porque o procedimento afeto ao Tribunal do Júri permite a produção de prova em Plenário de Julgamento.' (TJMG - Des. Pedro Vergada- voto vencido- RSE 1.0024.08.970753-3/001- $5^{\mathrm{a}} \mathrm{C}-$ pub 08/09/2009). 
Destaca-se que o Superior Tribunal de Justiça já se manifestou no sentido de afastar a aplicabilidade do artigo 155 do Código de Processo Penal Brasileiro, inclusive após o julgamento em plenário, conforme julgado abaixo colacionado:

HOMICÍDIO QUALIFICADO. JÚRI. DECISÃO FUNDAMENTADA EM PROVA TESTEMUNHAL COLHIDA NO INQUÉRITO POLICIAL. POSSIBILIDADE. SOBERANIA DO VEREDICTO. NULIDADE. NÃO OCORRÊNCIA.

Não há falar em ausência de fundamentação, nem em decisão manifestamente contrária a prova dos autos, na hipótese em que o conselho de sentença, acolhendo uma das versões apresentadas no julgamento, concluiu pela autoria do crime, com base nas provas testemunhais colhidas na fase investigatória. O tribunal de apelação somente poderia anular o julgamento do júri se a decisão do conselho de sentença, distanciando-se da prova dos autos, fosse absurda, arbitrária, teratológica, o que não ocorreu na espécie. (HC 44.374/SP - Quinta Turma - Rel. Min. Arnaldo Esteves Lima, DJU 10/12/2007, p. 401).

\section{Fundamentos}

A vida é o bem jurídico mais importante do homem, porque condicionador de todos os demais. Dessa forma, a Constituição Federal de 1988 descreveu o direito à vida como direito fundamental (artigo $5^{\circ} \mathrm{da} \mathrm{CF} / 88$ ), inclusive com alcance no âmbito internacional e universal (H. Kelsen).

O direito processual penal consubstanciou rito especial para processar e julgar os crimes dolosos contra a vida do Tribunal do Júri, com regras próprias.

Não é possível a aplicação de normas processuais penais, de forma irrestrita, no procedimento do Tribunal do Júri, porque possui regras diferenciadas.

$\mathrm{Na}$ instrução preliminar do procedimento do Tribunal do Júri, não se impõe nenbuma análise meritória e nem sanção alguma 
ao recorrente; a decisão tem natureza meramente processual, baseada na demonstração da materialidade e indícios de autoria delitiva.

O objetivo da instrução sumária é firmar a competência do Tribunal do Júri e garantir ao cidadão que possa ser julgado, no mérito, por jurados - juízes leigos -, consagrando o estágio filosófico máximo da democracia.

A obrigatoriedade em relação à produção probatória sob o crivo do contraditório, descrita no artigo 155 do Código de Processo Penal Brasileiro, atinge somente a sentença de mérito, em que se exige do magistrado o juízo de certeza, fundamentado, após apreciação dos elementos probatórios. Mesmo assim não há impedimento algum de que o magistrado venha proferir sentença condenatória, com fulcro em provas produzidas em fase inquisitorial e judiciais.

Nesse sentido:

TJSP - Registre-se que a nova redação do art. 155 do Código de Processo Penal veda a condenação rastreada unicamente em elementos coligidos na fase administrativa da persecução penal. (Ap.990.09.226423-0, 16 ${ }^{\mathrm{a} C}$. rel. Almeida Toledo. 14.12.2010, v.u.).

É notório que a natureza jurídica da sentença de pronúncia é diversa da sentença condenatória. Isso porque a sentença de pronúncia consubstancia uma decisão mista terminativa processual, na qual não se comina nenbum tipo de sanção, apenas se verifica os indícios de autoria delitiva e materialidade, cuja análise meritória será submetida aos jurados, na sessão de julgamento do Tribunal do Júri, nos termos do artigo $5^{\circ}$, inciso XXXVIII da Constituição Federal de 1988.

Não há o se falar na aplicação literal do artigo 155 do Código de Processo Penal Brasileiro neste procedimento especial, já que a pronúncia consubstancia somente um juízo de admissibilidade, 
restando afastada qualquer análise meritória, que, por determinação constitucional, somente pode ser realizada pelos jurados na sessão plenária do Tribunal do Júri.

Na sessão do Tribunal do Júri, inclusive, é possível nova produção probatória, inclusive oral, em plenário, para a livre apreciação dos jurados.

A possibilidade de produção probatória diversa daquela realizada na fase sumária, no plenário do Júri (oportunidade em que o mérito é apreciado), é uma peculiaridade deste procedimento especial. Inclusive, as partes podem pugnar pela imprescindibilidade da oitiva de testemunhas por elas indicadas.

Dessa feita, é infecunda qualquer discussão probatória na fase da pronúncia. Primeiramente, porque a pronúncia é decisão meramente processual que reafirma competência. No mais, na sessão do Tribunal do Júri, em que o mérito será analisado pelos jurados, há nova instrução probatória, inclusive com possibilidade de oitiva de novas testemunhas; portanto, é no veredicto do plenário que se discute o juízo de certeza.

Demonstrada a materialidade e indícios de autoria, a submissão do delito ao plenário do Júri, perante o corpo de jurados - leigos -, é imprescindível, inclusive amparada pela plenitude de defesa, porque este julgamento consubstancia a consagração máxima do sistema democrático, sob a ótica da teoria policentrismo e da comparticipação processual de Fazzalari e de Habermas, os quais consubstanciam bases filosóficas que justificam o contraditório. (NUNES, 2011, p. 202-260).

O procedimento do Júri é especial e deve obedecer as regras próprias, não sendo possível a aplicação irrestrita de institutos processuais, principalmente o artigo 155 do CPP.

Nesse sentido, a doutrina aduz sobre a pronúncia: 
Todavia, se o Juiz se convencer da existência do crime e de indícios suficientes de que o réu seja o seu autor, proferirá decisão de pronúncia. Esta, conforme vimos ao tratar da classificação dos atos jurisdicionais, é uma decisão interlocutória mista não terminativa, porque encerra, sem julgamento do mérito, a primeira etapa do procedimento dos crimes da alçada do Júri. A decisão interlocutória mista encerra o processo sem o julgamento do mérito. [...] Não se trata de decisão de mérito, pois, mesmo reconbecendo seja o réu o autor do crime, não se aplica nenbuma "sanctio juris". A decisão aí tem, evidentemente, caráter nitidamente processual. (TOURINHO FILHO, 2012, p. 163, grifo nosso).

[...] É preciso considerar que a decisão de pronúncia somente deve revelar um juízo de probabilidade e não o de certeza. (OLIVEIRA, 2011).

O Supremo Tribunal Federal já firmou jurisprudência no sentido de admitir somente provas produzidas em fase inquisitorial para fundamentar a pronúncia.

A razão da distinção de tratamento probatório no Tribunal do Júri, na fase sumária, é que basta a demonstração da materialidade e indícios suficientes de autoria delitiva para a prolação da pronúncia, por sua própria natureza. Basta, pois, a constatação do juízo de admissibilidade e não de certeza.

$\mathrm{O}$ art. 413 do Código de Processo Penal aduz que finda a fase do sumário dos crimes de competência do Tribunal do Júri, o acusado será pronunciado quando o Juiz se convencer da materialidade do fato e da existência de indícios suficientes de autoria. Presentes os referidos requisitos, o magistrado deve submeter a apreciação meritória aos jurados (juízes leigos), para análise meritória, em sessão do Tribunal do Júri, por ser garantia fundamental constitucional basilar ao Estado Democrático de Direito.

Nesse passo, eis a jurisprudência pátria a respeito do juízo de admissibilidade da pronúncia: 
STJ - 'Todas as acusações que tenham ao menos possibilidade de procedência deverão ser submetidas ao Tribunal Júri, juiz natural da causa, com esteio no art. 408 do Código de Processo Penal.' (HC 147874- RJ, 5T. rel. Gilson Dipp, 16/12/2010,v. u.).

STF - 'É firme a jurisprudência deste Supremo Tribunal no sentido de que a decisão de pronúncia é mero juízo de admissibilidade da acusação, motivo por que nela não se exige a prova plena, tal como exigido nas sentenças condenatórias em ações penais que não são da competência do júri, não sendo, portanto, necessária a prova incontroversa da existência do crime para que o acusado seja pronunciado. Basta, para tanto, que o juiz de convença daquela existência.' (HC 98791/ES, 1. T. J. 28.09.2010. v. u., rel. Cármen Lúcia).

É, pois, necessário que os operadores do direito observem as peculiaridades do rito do Tribunal do Júri, aplicando as normas processuais penais somente em relação às suas lacunas, no que lhe for compatível.

Assim, nota-se que a jurisprudência pátria, de forma acertada e em consonância com as peculiaridades do procedimento especial do Tribunal do Júri, afastou a aplicação do artigo 155 do Código de Processo Penal na fase sumária do referido procedimento especial, confirmando, inclusive no Pretório Excelso, a possibilidade da decisão de pronúncia basear-se somente em provas inquisitoriais.

\section{Referências bibliográficas}

CARVALHO, Kildare Gonçalves. Direito Constitucional. 15 ed. Belo Horizonte: Del Rey, 2009. 1572 p.

HÄBERLE, Peter. Hermenêutica Constitucional: a sociedade aberta dos intérpretes da constituição: contribuição para a interpretação pluralista e "procedimental" da constituição. Porto Alegre: Sérgio Antônio Frabris Editor, 2002.

LEAL, Rosemiro Pereira (coord.). Estudos Continuados de Teoria do Processo. Porto Alegre: Síntese, 2000. 188 p. 
NUCCI, Guilherme de Souza. Código de Processo Penal Comentado. 10 ed. São Paulo: Editora Revista dos Tribunais, 2011. 1310 p.

NUCCI, Guilherme de Souza. Tribunal do Júri. 2. ed. São Paulo: Revista dos Tribunais, 2011.

NUNES, Dierle José Coelho. ProcessoJurisdicional Democrático. 1. ed. Curitiba: Juruá, 2011. 282p.

OLIVEIRA, Eugenio Pacelli. Curso de Processo Penal. Rio de Janeiro: Lumen Juris, 2011. 974 p.

QUEIROZ, Cristina. Direitos Fundamentais Sociais. Coimbra: Coimbra Editora, 2006. 254 p.

TOURINHO FILHO, Fernando da Costa. Código de Processo Penal Comentado. 12. ed. São Paulo: Saraiva, 2009, v II. 850 p.

TOURINHO FILHO, Fernando da Costa. Processo Penal. 34. ed. São Paulo: Saraiva, 2012, v. IV. 685 p. 